\title{
Diana Alvarez-Marin
}

\section{Atlas}

\section{The universe is a sphere of which the centre is everywhere and the circumference is nowhere. \\ Nicholas Cusanus}

$\mathbf{L}$

et us imagine, for the sake of a peculiar navigational task, the articulation of an Atlas that builds itself as we navigate through it. This Atlas is a collection of atlases. It collects a multiplicity of models under a common narrative, where navigation from model to model is enabled while discovering a personal interest. Each one of these models works like a small atlas, reconstructing the idea of a continuum by infinitesimal approximation. They give us hints about a planet we are eager to discover, their renderings out of the abstract manifest a clear intention and directionality. Any path is possible, and even if collapsed at multiple occasions, it preserves a topological continuity like a thread, woven into a fabric or guide through a labyrinth. Such a constellation of models can constitute a new Atlas on its own, an Atlas of Atlases.

After the Titanomachy, ${ }^{1}$ the Titan Atlas was doomed by Zeus to support the celestial vault on his shoulders for eternity. Like a vicarious head, this vault is a capital that circulates, a cosmological model that Atlas sustains through the play of singular figures, yet its architectonics do not remain fixed but unfinished. It is an idea of the world, which remains itself inaccessible, yet that tries to grasp continuously by infinitesimal approximation. As our lines of sight change, our Atlas remains as the 


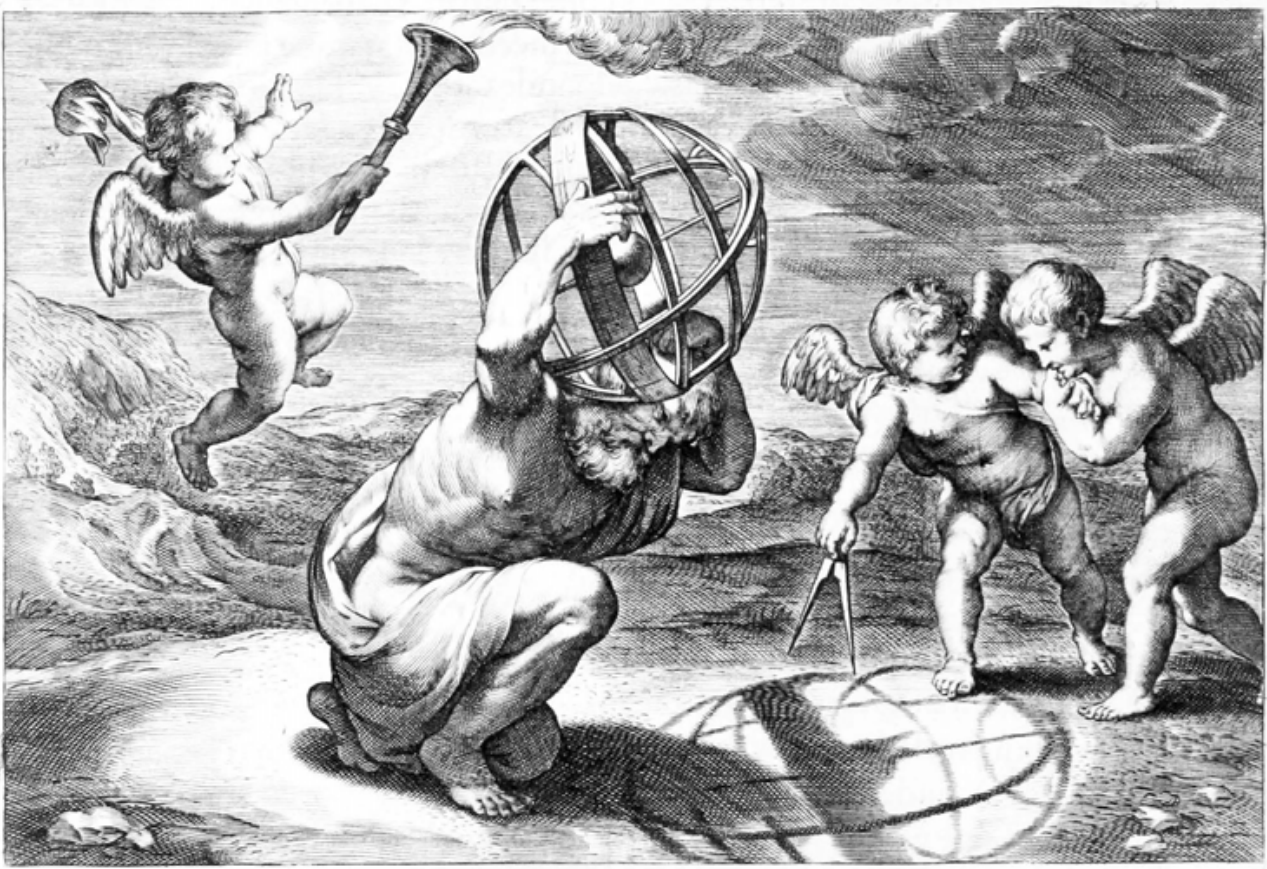

Fig. 1 Illustration by Rubens for François d'Aguilon's Opticorum Libri Sex demonstrating how a stereographic projection is computed (1613).

architectonic construction that binds together possibilities, a platform connecting multiple locals, while preserving their relation to a global.

We might wonder what kind of territory such an Atlas explores. More precisely, we will delve into the world of messages and communication, where translations, encryptions and decryptions take place. To articulate a more accurate idea of its mechanics and activations, we will study in depth three prominent Atlases and their particular gestures: Warburg's Mnemosyne infinitesimal variation, Richter's transient multiplicity and Serres' universal intermediate. The mathematician Fernando Zvalamea enumerates briefly this triptych in the chapter
'Disorientation' in Ariadna and Penelope, Networks and Mixtures in the Contemporary World, ${ }^{2}$ where by the means of this gesture he tries to identify methods of navigation inside the moving dialectics of our time, where one can be in one, any and no place at the same time. 

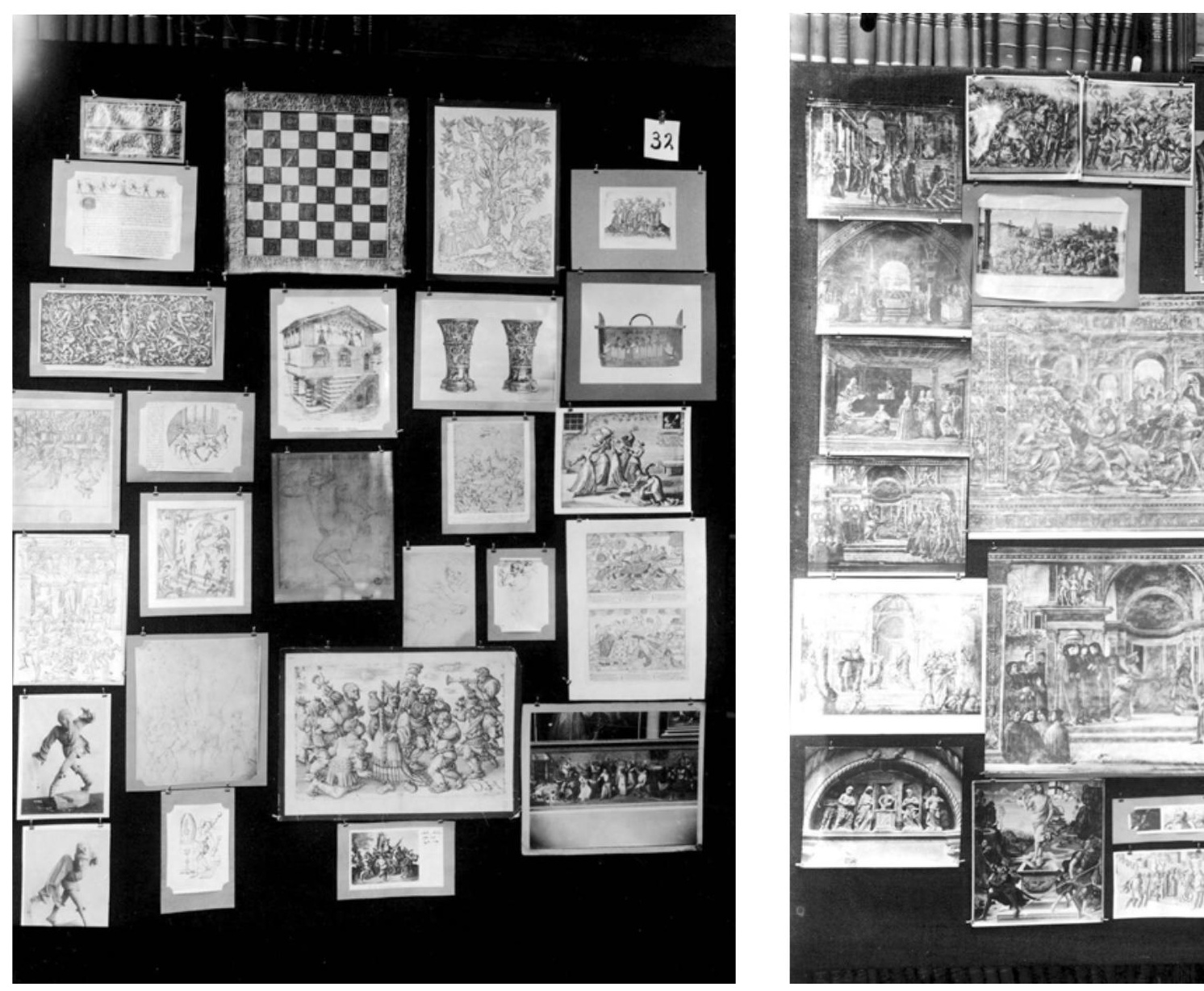

Fig. 2 Aby Warburg's Atlas Mnemosyne, in order of appearance:

Panel 32: Bacchic carnival retinue

Panel 45: Gestures to a superlative degree: from grisaille to painted reality

Panel 48: Fortune and Renaissance Man: predestination and individual freedom 

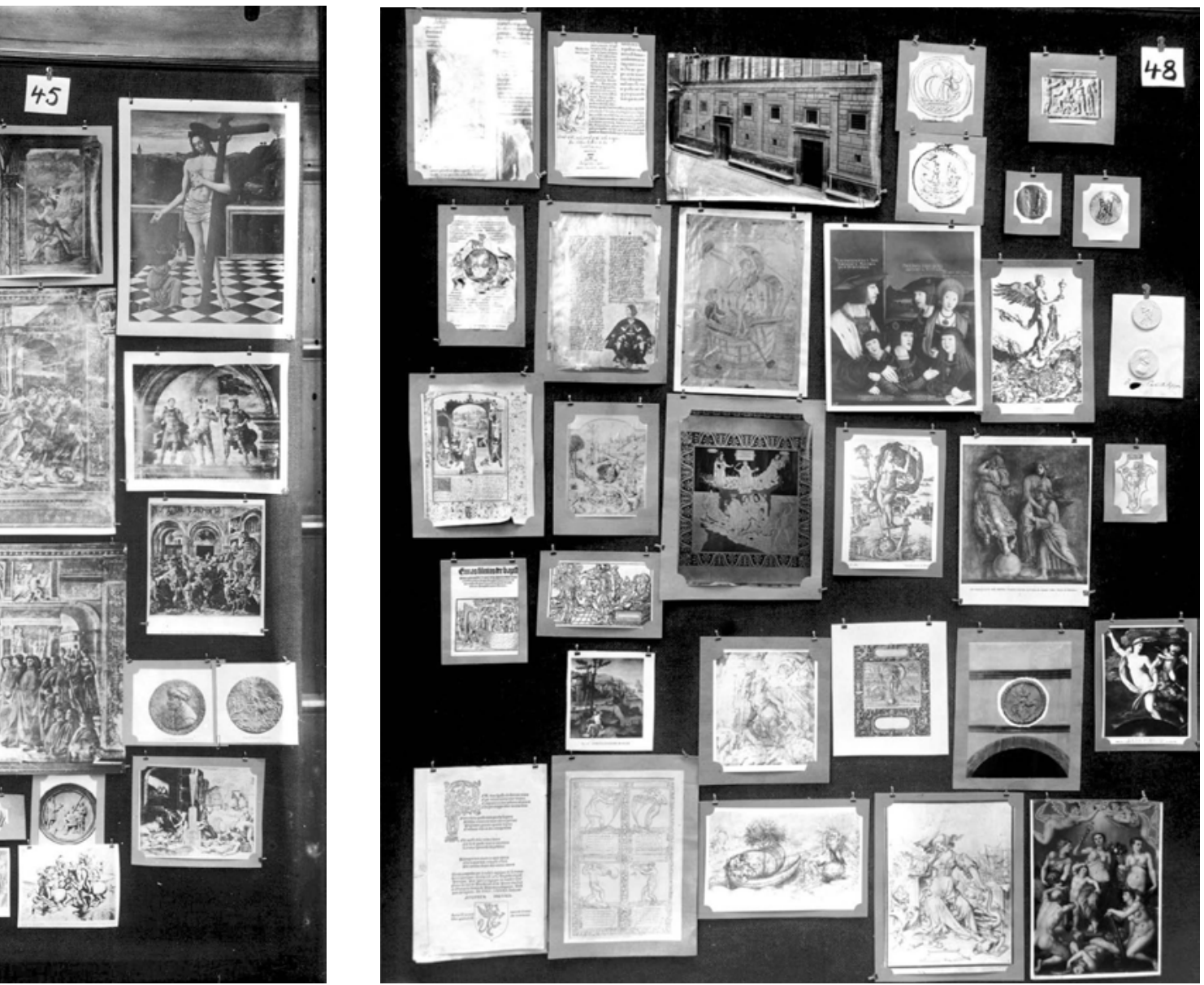


\section{Warburg's Mnemosyne Atlas, "a ghost story for truly adult people." ${ }^{3}$}

The art historian Aby Warburg ${ }^{4}$ first conceived the Mnemosyne Atlas in 1925 after his release from Ludwig Binswanger's psychiatric clinic in 1924; he actively developed it in 1928 and continued it until his death in $1929 .{ }^{5}$ During his mental illness, Warburg was haunted by a demonic possession "of lifeless things," 6 that perhaps made him reevaluate the distance between objects and subjects in his work. Mnemosyne consisted of 40 wooden panels covered with black cloth, on which were pinned nearly 1,000 pictures from books, magazines, newspapers and other daily life sources ${ }^{7}$ without captions and only a few texts.

With his Atlas, Warburg aimed at creating a model of memory and continuity of experience achieved by a materialist project before the arrival of German fascism, which he feared would ravage social memory. In addition, Warburg aimed at challenging the boundaries and conventions established in the studies of art history. Benjamin $\mathrm{H}$. D. Buchloh argues that "Warburg's Atlas reiterated his lifelong challenge to the rigid and hierarchical compartmentalisation of the discipline of art history through an attempt to abolish its methods and categories of exclusively formal or stylistic description.”

Outside of a given historical or geographical continuity, the Atlas explores how new meanings can be articulated by the movement of styles and themes, and their recurrence. With this gesture, Warburg offers a dynamic "thought-space" [Denkraum] where images show objective and subjective forces simultaneously shaping culture. Warburg believed that "images, when juxtaposed and then placed in sequence, could foster immediate, synoptic insights into the afterlife of pathos-charged images depicting what he dubbed 'bewegtes Leben' (life in motion or animated life)." "

The movement of this Atlas goes between the part and the whole, between various discourses and modes of representation. Warburg believed that human expression could provide-despite the gaps in space and time - the possibility of grasping a conceptual unity. Confronting us with images rather than their iconological interpretation, the Atlas restores the initial experience of a spectator and their intuition of how "a multiplicity of artistic and historical details can be reconciled with the unity of perception." ${ }^{10}$

Mnemosyne addresses the tension between the continuity of the real, the discreteness of our partial representations and their 'glueing, to try to reconstruct a continuous 'film' of the world. Warburg's effort tends towards dissolving borders and giving emergence to the continuous, blurry and indeterminate by paradoxically introducing minimal variations of a theme, like in an infinitesimal approximation towards it. 


\section{Gerhard Richter's Atlas}

Warburg's effort is extended in Gerhard Richter's Atlas, a collection of photographs, newspaper cuttings and sketches growing and constantly evolving, now exceeding eight hundred panels and spanning over a period of almost five decades. The individual panels reflect different phases of Richter's life and work: Although Gerhard Richter had already begun collecting photographs and press cuttings in the 1960s, he started working on the Atlas in the early 1970 s by arranging his own and other family photographs on paper. Some of these photographs were used as source images for paintings. While drawings, collages and sketches appear throughout the Atlas, photography is the central focus. Even though his initial purpose was unknown, even to Richter himself, he affirms: "My motivation was more a matter of wanting to create order-to keep track of things. All those boxes full of photographs and sketches weigh you down, because they have something unfinished, incomplete, about them."11

Richter tries to create an unfinished sense of order, allowing his Atlas to preserve a dynamic complexity where meaning can emerge out of resonance, and whose relationships remain ongoing, vivid and alive as a transient multiplicity. As an unfinished articulation, always in continuous reinvention, the Atlas cannot be approached as a totality. One single image can reverberate throughout the whole Atlas as the collection is constantly changing. One single image can reactivate a panel that seems dormant or finished by coming in or out. One single image can become an entry door to a new whole navigation thread through Richter's instrument and its complex web of interconnections.

Simultaneously, in a pendular movement, the integration of the differential records of the extreme diversity of the world appears in each panel, where the artist explores correlations and correspondences into themes or genres. Photographs, sketches, abstractions and figures, fields of colour, mountains and cities, seas and rooms, clouds and vegetation, sequences of landscapes alongside urban aerial views, flowers and forests. A transient multiplicity with a thousand complementary perspectives where the great contradictions of our time can emerge. Explicit registry of all kinds of dialectics, it faces at the same time ruptures, crises, traumas. The Atlas can be experienced as a pendular movement between singular localities and its dynamic and ever-changing body of work, linear and cyclic, ordered and labyrinthic, open to infinite interpretation and analysis.

Richter also explores the question of the aesthetic value of the 'original' and the 'copy'. The Atlas challenges usual perspectives, by presenting a recursive iteration of representations, where a copy, as it resonates with other instances of representation or is continuously being re-contextualised, becomes something new and different from the original itself. These transient multiplicities and inflexions around a theme open a continuous field, where one can be in one and every place at the same time, and through which one can navigate with an intentional orientation. 


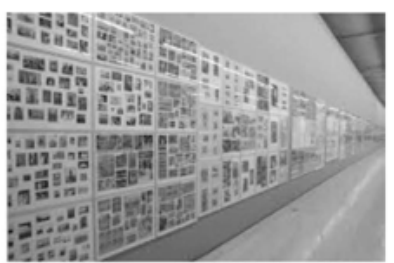

Atlas ; Art $=$ Gerhard Richter

gerhard-richter,com

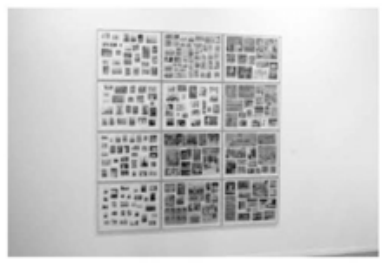

Gerhard Richter: Atlas | "Objectivités flicks.com

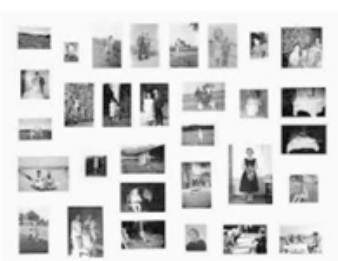

Gerhard Richter "Atlas" at the

moussemagazine.it

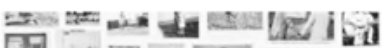

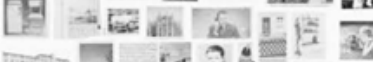

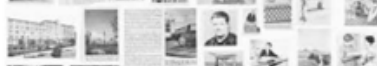

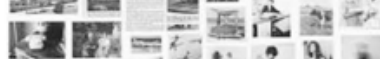

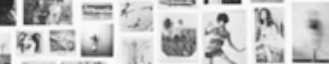

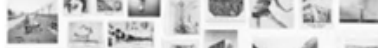

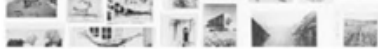
The order of Memory: Gerhard Richter's blog.qagoma.qld.gov.au

\section{Dis Na: 춘 0 -

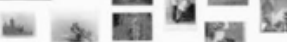

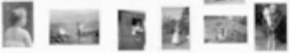

Gerhard Richter - Atlas * File Magazine file-magazine.com

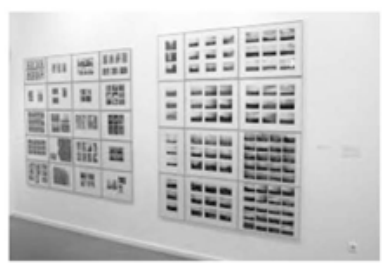

Gerhard Richter: Atlas | "Objectivités flicks.com

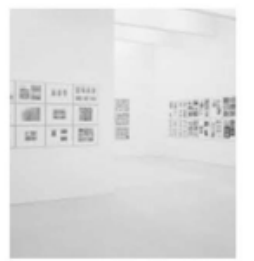

Gerhard Richter: Atlas | Ex. diaart.org

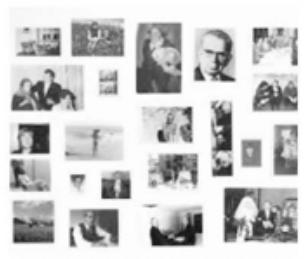

Album photos [6] > Art * Gerhard R. gerhard-richtercom

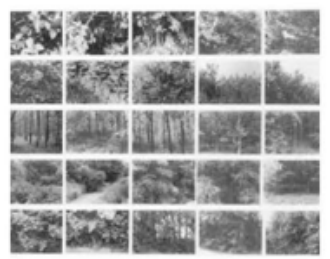

gerhard richter, atlas-trees-collection. pinterest.com

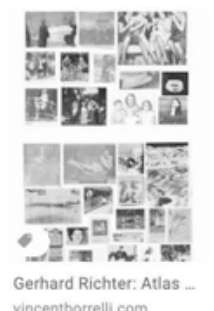

vincentborrellicom

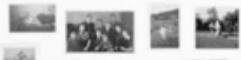

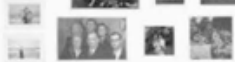

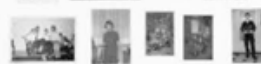

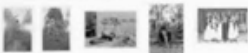

Album Photos [2] > Art * Gerhard R gerhard-richter.com

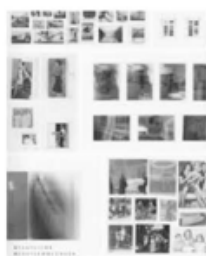

Atlas > Exhibitions $>\mathrm{Ge}$. gerhard-richter.com

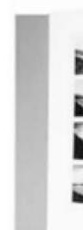

Exquisit: artbook

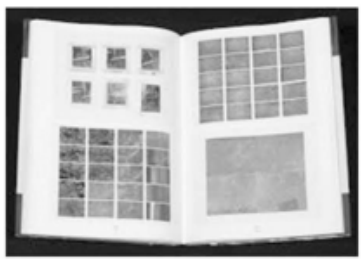

Gerhard Richter

manhattanrarebooks.com

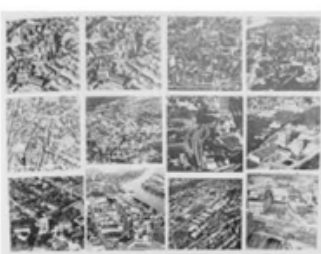

Atlas Gerhard Richter First Edition Sign. raptisrarebooks.com

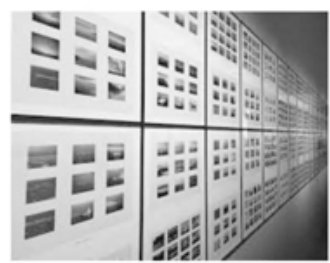

Gerhard Richter's Atlas at the GOMA bartdaems.com

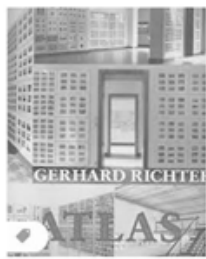

Gerhard Richter: Atlas: ... amazon.com

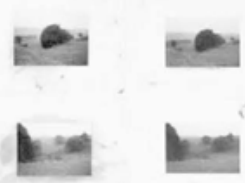

The order of Memory: Gerhard Rich. blog.qagoma.qld.gov.au

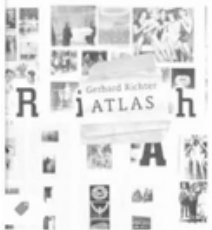

Atlas Gerard Richter (P. amazon.com

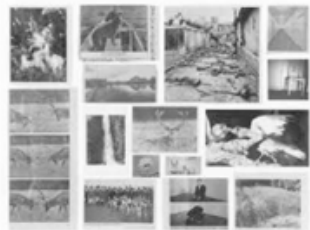

photos [11] > Art * Gerhard Richter gerhard-richter,com

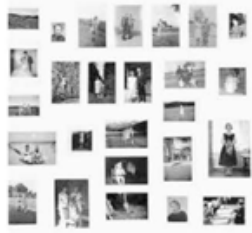

GERHARD RICHTER: ATLAS | .. superpaper.de

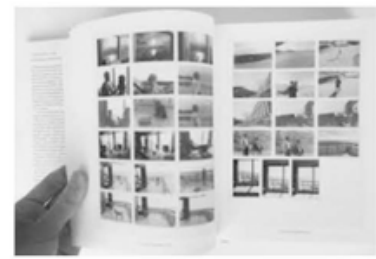

Gerhard Richter - Gerhard Richter catawiki.com

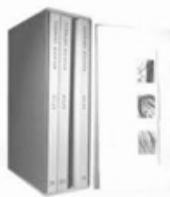

Exquisite: Gerhard Ric artbook.com

Fig. 3 Google Image Search results for "Gerhard Richter Atlas". 


\section{Michel Serres' Atlas}

Both the infinitesimal variation of Warburg and the transient multiplicity of Richter find themselves synthesised in Serres' universal intermediate. Serres' Atlas (1994) aims at mapping the state of matter of the contemporary world of information and communication, where familiar categories like nature, city, object, subject, local, global, are imbricated and are influenced by virtual spaces or "the vicinity of the real." Serres claims that to navigate in this new space of the world where "the being expands," we need to understand that the centre is everywhere and the circumference nowhere, ${ }^{12}$ recalling both the infinitesimal and the transient.

Considering this new space of communications, Serres invites us to extend geography "towards a new cartography, containing virtual spaces" where Euclidian distances are irrelevant, and new heterotopic articulations can emerge. He writes, "let us trace out the map, real and imaginary, unique and double, ideal and false, virtual and utopian, rational, analytic, of a world where the Alps can change place with the Himalayas, such that their forms reply to each other, and that the callings from here correspond to the groanings of the excluded there." 13

\section{Global and Local}

The relationship between the global and the local is central to Atlas: every local implies the global and the global depends on the multiplicity of all its locals, as every local point becomes a centre in the network and is in virtual communication with all other locations. The network becomes, therefore, the geometry where the transitions between local and global and global and local can happen. The virtuality of such networks and communication techniques allows us to be anywhere from any place in real-time, a condition that Serres refers to as "Pantopia.” Each of us, locally connected to the global through the network, can be simultaneously a global errant and a local sedentary.

The paradox of finding the universal in the uniqueness of the place is an invitation to meditate on the globality of these localities. Atlas addresses the intermediate concept between local and global as "the most general problem of a plan or map." Every atlas, he affirms, "shows spacetime mosaic models of diversity, final image of place, of time and of heterogeneous networks."14 But also, "this mosaic model brings together all the contemporary questions about balance, always declined in the plural, as well as the different conceptions, mainly chaotic, that we can have of space, evolution and time." ${ }^{15}$

\section{The Horla: The Character of Space or How We left Euclidean Space}

Serres uses Maupassant's story The Horla as an index to the model of space that Atlas explores. The "hors" indicates the exterior, the remote, the inaccessible; while the "là" indicates the nearby, the adjacent, the reachable. The Horla indicates therefore the tension between these two registers. In Maupassant's story, "the narrator sees a shadow, an opaque and transparent ghost that, in front of the mirror, intercepts the images without at the same time having an exact image in the mirror. What a strange shadow, to be and not to be at the same time, present and absent, here 
and there, a contradictory third party!"16 For Serres, the story shifts from the world of the familiar to the world of the uncanny, from the rational to the irrational, in the same way as the Euclidean space of rigid metrics shifts towards a topological space that stretches and folds.

These 'extensions' are an exercise in projective geometry that maps this fictional discourse onto topological surfaces by describing positions with prepositional or relational expressions. This topological space connects the actual through the virtual: through language, imagination and communication. For instance, when two people have a conversation, an in-between site of transit appears, an 'outside-of-there', an "hors-là." As Marcel Henaff points out, "contemporary communication technologies do not alter our belonging to a site, or disturb a niche destined to remain local, because we have always been living elsewhere; nor do they only prolong our sensory or motor organs. They do better. They actualise and realise our representations: the imagination into images, the voice into messages and the hors-la into networks of connected sites." ${ }^{17}$

\section{World and Flesh}

Finally, there is a self-referential gesture in Serres' Atlas, where the metatopology of events, or the collection of connections and messages, becomes the world of communication itself. Using recurrent mythic and religious figures, Serres argues that the word has become flesh (of the world), and the flesh has become the word that flies to 'other' places of the world without the necessity of a present body, like a shapeless and absent body that collects, in potency, all possible shapes.
Serres writes: "This is my body: the book I write is more the flesh of my flesh than my own flesh. And also, like that of an angel, this subtle body can virtually depart, fly, speak in other places without the present body." 18 This fluid and intimate incarnation would suggest that the articulation of a personal atlas overlaps with the articulation of one's persona as a brand. Each one of us is therefore invited, through navigation to the discovery of one's self, or even better, one's world. Yet, this idea of identity, like the one of the shapeless body that flies to places, is not given nor frozen. It takes us to another level of thinking where a thing can be itself and its opposite and all the spectrum in between, allowing for the coexistence of determinacy and indeterminacy, the universal and the particular, the part and the whole, the local and the global. 


\section{Atlas and its Invariances}

Which are the invariances of the Atlases that we have jauntily gathered? Atlases start with the invisible. They adapt and consider the multiple and changing viewpoints of a world rather than defining a fixed frame of it. Such a frame is not static, instead it is in itself a 'pendular movement': between the whole and its parts, the global and its locals. These synthetic and projective operations of 'transient multiplicities' take place in a dynamic 'thought-space', a 'universal intermediate', an 'hors-la' or a 'space of communications'. Atlases are therefore the modelling of an evasive environment that requires a personal interest or inclination, making the relationship between the 'original' and the 'copy' not one of repetition but one of differentiation. If a viewpoint can then be called an image (not as a mere copy but as a creative moment on its own terms), each image in a world 'resonates' with all the others and becomes 'an entry door' around which the whole can circulate.

\section{Through this 'metatopology', an explorer} navigates their world with their Atlas and while doing so, articulates their identitytheir brand, their mask - projecting and rendering a particular inclination towards it. They learn how to behave in a space that does not stay still, as it becomes relative to the articulation of moving centres and identities. Their navigational journey affects them globally as much as it does locally and, like an atlas, depends on a projective point that comes from outside, where every projection is a personal articulation of the world with a certain modulation, question, interest and contextual space of existence. Yet, no one knows which came first, the atlas or its navigation: since one synthesises the other self-referentially. Perhaps, what an atlas gives us at the end is an atlas of the self while it whispers: I don't believe in one story but in the collective force of many. "I am legion: an innumerable set of others." ${ }^{19}$

1 In Greek mythology, the Titanomachy (/, tart'noməki/

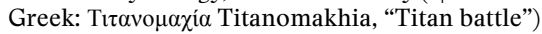
was a ten-year series of battles fought in Thessaly, consisting of most of the Titans (an older generation of gods, based on Mount Othrys) fighting against the Olympians (the younger generations, who would come to reign on Mount Olympus) and their allies. This event is also known as the War of the Titans, Battle of the Titans, Battle of the Gods, or just the Titan War. The war was fought to decide which generation of gods would have dominion over the universe; it ended in victory for the Olympian gods. Wikipedia, s.v. “Titanomachy," last modified January 10, 2020, 21:13,

https://en.wikipedia.org/wiki/Titanomachy

2 Zalamea F. Ariadnay Penélope. Redes y mixturas en el mundo contemporáneo. Ediciones Nobel. 2004.

3 Agamben G. Aby Warburg and the nameless science. Potentialities: Collected essays in philosophy. 1999:89-103.

$4 \quad$ Warburg A. Der Bilderatlas Mnemosyne. Akademie Verlag; 2008.

5 Buchloh BH. Gerhard Richter's "Atlas": The Anomic Archive. October. 1999 Apr 1:117-45. Available on https://www.jstor.org/stable/779227

6 Fritz Saxl. Rede gehalten bei der Gedächtnis-Feier fuir Professor Warburg am 5. Dezember 1929.

WIA I.10.8.1, p. 11.

7 Gombrich, Ernst H., and Fritz Saxl. Aby Warburg: An Intellectual Biography; with a Memoir on the History of the Library. Phaidon, 1986.

8 Buchloh BH. Gerhard Richter's "Atlas": The Anomic Archive. October. 1999 Apr 1:117-45. Available on https://www.jstor.org/stable/779227

9 Mnemosyne, Meandering through Aby Warburg's Atlas. Christopher D. Johnson. Accessed January 20, 2020. https://warburg.library.cornell.edu/about

10 Johnson, Christopher D. Memory, metaphor, and Aby Warburg's Atlas of images. Cornell University Press, 2012.

11 Elger, Dietmar, and Hans-Ulrich Obrist, eds. Gerhard Richter: text: writings, interviews and letters, 1961-2007. Thames \& Hudson, 2009.

12 Cusanus, Nicholas. Of learned ignorance. Wipf and Stock Publishers, 2007.

13 Michel, Serres. Atlas. Paris, Julliard, 1994.

14 ibid

15 ibid

16 ibid

17 Hénaff, Marcel, and Anne-Marie Feenberg. Of Stones, Angels and Humans: Michel Serres and the Global City. SubStance 26, no. 2. 1997: 59-80.

18 Michel, Serres. Atlas. Paris, Julliard, 1994.

19 ibid 